\title{
The Short-Term Results of Pyrocarbon Lunate Implants in Patients with Advanced Kienböck's Disease
}

\author{
HJA Zijlker1,2, R Fakkert'1,2, J van Rijn ${ }^{2,3}$ and A Beumer ${ }^{2,4}$ \\ 1Department of Plastic, Reconstructive and Hand Surgery, AUMC, location VU University Medical Center, Amsterdam, The Netherlands \\ ${ }^{2}$ Department of Orthopaedic Surgery, Upper Limb Unit, Amphia Hospital, Breda, The Netherlands \\ 32Department of Orthopedic Surgery, Erasmus MC, Rotterdam, The Netherlands \\ ${ }^{4}$ Coronel Institute of Occupational Health, Amsterdam Public Health research institute, AUMC, location Academic Medical Centre, Amsterdam, The \\ Netherlands
}

${ }^{\star}$ Corresponding author: Beumer A, Department of Orthopaedic Surgery, Upper Limb Unit, Amphia Hospital, P.O. Box 90158, 4800RK Breda, The Netherlands; Tel: +31-0765954453; Email: achbeumer@hotmail.com

Received: April 02, 2019; Accepted: April 20, 2019; Published: May 28, 2019;

\begin{abstract}
Purpose: The purpose of this study was to evaluate the short-term results of pyrocarbon lunate implants (PLI) (Ascension Orthopaedics, Austin, Texas).

Methods: Patients with advanced Kienböck's disease who received PLI were prospectively followed for one year. The implant outcomes were assessed by pre- and postoperative questionnaires and physical examination.

Results: six patients (six implants) with Kienböck's disease grade IV were included in this study. All implants remained in situ at one-year follow-up. Pain was satisfactorily reduced in five patients. Grip strength improved slightly in three patients and worsened in two. The DASH scores improved in four patients with mean 26 points. Five patients returned to their previous jobs and the two patients whom did sport could resume it. Three patients had to be mobilized under general anaesthesia because of a severely stiffened wrist.
\end{abstract}

Conclusions: The short-term results of the PLI are suboptimal, probably largely due to severe stiffening of the wrist. Nonetheless, long-term results are necessary to adequately assess the longevity and functionality of this implant and to assess which postoperative treatment would provide the optimal clinical result. Type of study/level of evidence: Therapeutic, level IV.

Keywords: Lunate Implant, Pyrocarbon, Results

\section{Introduction}

In 1910, Kienböck [1] was the first to describe the radiological signs of isolated lunatomalacia, currently known as Kienböck's disease. Despite many years of clinical experience and research, the cause of this disorder still remains unclear. Morphological variations such as the negative ulnar variance, the particular pattern of vascularity and repetitive trauma may be predisposing factors, suggesting a multifactorial aetiology [2]. Kienböck's disease is divided into 4 stages and can be diagnosed by conventional radiography [3] and Magnetic Resonance Imaging (MRI) [4].

Kienböck's disease can be surgically treated. Patients with negative ulnar variance, without (radio) carpal osteoarthritis and Kienböck's disease stage I-IIIa can be treated by a radial osteotomy [5]. Patients with neutral ulnar variance, no (radio) carpal osteoarthritis and Kienböcks disease stage I-IIIa can be treated by revascularisation [6-8]. Patients with Kienböck's disease stage IIIb-IV can be treated by proximal row carpectomy, partial or total wrist arthrodesis or arthroplasty: resulting in limited mobility and function of the wrist. The lunate implant was developed to maintain wrist function in patients with severe Kienböck's disease.
There are only few reports in the literature that report on the clinical outcomes of pyrocarbon lunate implants [9]. We present a case series with short-term outcomes of patients with this type of pyrocarbon lunate implant.

\section{Patients and Methods}

\section{Study Design}

All patients with advanced Kienböck's disease who received this pyrocarbon lunate implant (Pyrocarbon Lunate prosthesis, Ascension Orthopedics, Inc, 8700 Cameron Road, Suite 100, Austin, TX 78754 USA) were identified at the Amphia Hospital in Breda, The Netherlands. The inclusion criteria were patients with wrist pain as a result of Kienböck's disease grade IIIb or IV. The exclusion criteria were patients who performed heavy labour, patients with osteoarthritis of the radio- or midcarpal joint other than the lunate fossa and lunatecapitate joint and patients who received a prior surgical treatment for their wrist complaints. Informed consent was obtained before implant insertion. Relevant data were extracted from the medical records: demographics, medical history, profession, affected wrist and result of the Magnetic Resonance Imaging (MRI), This study's level of evidence 
is IV based on the absence of a control group and was approved by the Medical Ethical Committee at the Amphia Hospital in Breda, The Netherlands.

\section{Surgical Technique}

Surgery was performed under general anaesthesia and tourniquet control. A longitudinal incision on the dorsum of the wrist was made. The sensory branches of the radial and ulnar nerves were preserved. After identification of the third compartment of the extensor retinaculum, the compartment was opened to identify the extensor pollicis longus tendon, which was held to the radial side. The fourth extensor compartment was elevated from the radius and capsule and held ulnarly. The dorsal capsule was then incised, creating a distally based capsule flap. The degenerative lunate was identified and removed. Two K-wires fixated the triquetrum and scaphoid to the capitate. A $3.5 \mathrm{~mm}$ hole was drilled from the ulnar side of the scaphoid towards the volar aspect of the scaphoid. A $2 \mathrm{~mm}$ hole was drilled from the radial side of the triquetrum towards the dorsal side of the triquetrum. On the volar aspect of the wrist, two small incisions were made to reach the flexor carpi radialis tendon. The radial third of the Flexor Carpi Radialis (FCR) tendon was harvested leaving the distal attachment inserted. The FCR tendon graft was tunnelled through the scaphoid. Two Mitek-anchors were inserted, one in the scaphoid and one in the triquetrum. The tendon was guided through the volar hole of the prosthesis and through the hole in the triquetrum towards the ulnar side. Two wires of the anchors (one of each anchor) were guided through the volar hole of the prosthesis too. These wires were attached to each other. The position of the prosthesis was controlled by fluoroscopy. The other wires were put through the dorsal hole of the prosthesis and attached to each other while closing the 'gaps' radialy and ulnarly of the lunate. A third Mitek-anchor was placed into the scaphoid. Two gutters were created on the dorsum of the triquetrum en scaphoid. The remaining FCR tendon graft on the dorsal side of the triquetrum was positioned into the gutters towards the scaphoid and attached to the scaphoid using the wires of the third Mitek-anchor. The position of the prosthesis was checked again with fluoroscopy to assure an anatomical position. The capsule and skin were closed by sutures. A forearm cast was worn for six weeks. The K-wires were removed after six weeks and active mobilization of the wrist was started. For another six weeks a removable forearm splint was worn during stressful moments.

\section{Clinical Evaluation}

The PLI outcome was assessed by questionnaires and physical examination. Grip strength (measure by the Jamar handdynamometer), range of motion and the Disabilities of the Arm, Shoulder and Hand (DASH) questionnaire [10] were measured preoperatively and at one-year follow-up. Furthermore, return to work and sport, complications and patient satisfaction on pain reduction were evaluated.

\section{Radiological Evaluation}

$\mathrm{X}$-rays were performed postoperatively and at one-year followup to evaluate the pyrocarbon lunate implant position, intercarpal distance and progression of disease.

\section{Results}

Six patients (six implants, four females and two males) with Kienböck's disease grade IV were included in this study (Table 1). The mean age was 35 years (range 23 to 47 years). The dominant hand was involved in one patient. Preoperatively, all patients experienced wrist pain at rest that worsened after activities.

\section{Clinical Evaluation}

All six implants remained in situ at one-year follow-up. Five patients were satisfied with the pain relief. Grip strength improved slightly in three patients and worsened in two patients. Range of motion improved in two of the six patients. The DASH scores improved in four patients with mean 26 points and worsened in two patients with mean nine points. Five patients returned to their previous jobs and the two patients whom did sport could resume it.

\section{Complications and Revisions}

A K-wire was infected in one patient. The $\mathrm{K}$-wire was removed and the patient was successfully treated with oral antibiotics. The wrists of three patients were severely stiffened and were remobilized under general anaesthesia. None of the implants needed revision.

\section{Radiological Evaluation}

Analysis of radiographs showed that the scapho-lunate distance increased after removal of the K-wires in all six six patients. However, at one-year follow-up, this distance did not increase and there was no progression of disease (Figure 1). Furthermore, five wrists developed dorsal intercalated segment instability and one developed volar intercalated segment instability.

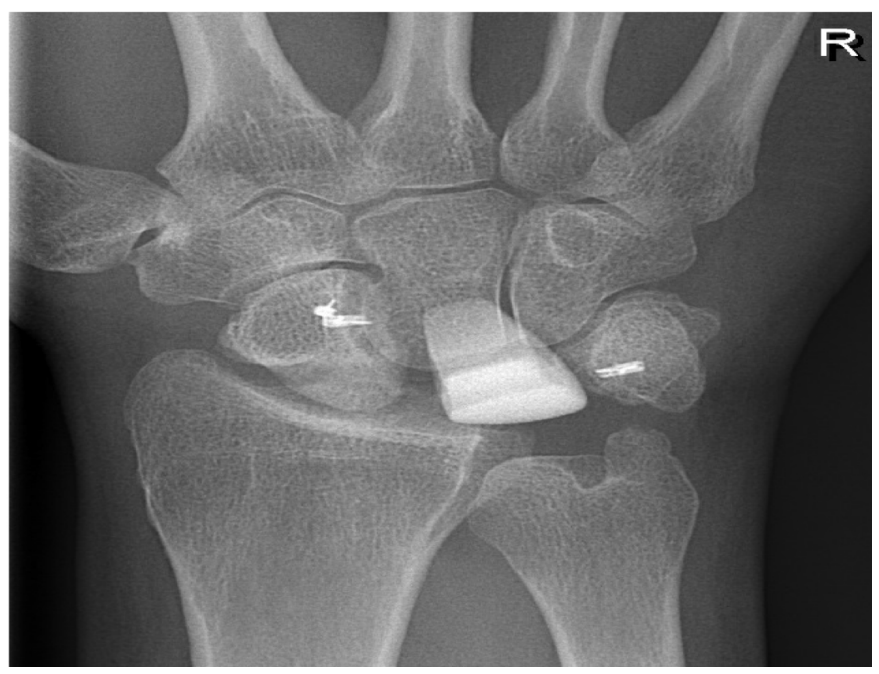

Figure 1. The anterolateral view of the pyrocarbon lunate implant at one-year follow-up.

\section{Discussion}

The aim of this study was to determine the short-term results of the pyrocarbon lunate implant. Lunate implant arthroplasty has been used as treatment for advanced Kienböck's disease for more than 60 years. In contrast to the silicon lunate implant, with a high incidence of silicone cysts (78\% after 27 years follow-up) [11], 
the titanium lunate implant has promising long-term results [12]. Although not mentioned by these authors, titanium might give rise to tissue reactions. Compared to titanium, pyrocarbon is more similar to cortical bone and transfers the load more effectively, potentially limiting bone resorption. Although Pyrocarbon implants might break, they are biologically inert and biocompatible resulting in a low tendency to wear and tissue reactions. Furthermore, pyrocarbon is less susceptible for wear when compared to titanium [13].

Table 1. Characteristics, clinical outcome and complications of patients with the pyrocarbon lunate implant.

\begin{tabular}{|c|c|c|c|c|c|c|c|c|c|c|c|c|c|}
\hline \multirow{2}{*}{$\begin{array}{l}\text { Case } \\
\text { no. }\end{array}$} & \multirow{2}{*}{ Age } & \multirow{2}{*}{$\begin{array}{l}\text { Kienböck's } \\
\text { disease } \\
\text { stage }\end{array}$} & \multicolumn{2}{|c|}{ Grip strength (kg) } & \multicolumn{2}{|c|}{ Flexion/extension } & \multicolumn{2}{|c|}{ DASH } & \multirow{2}{*}{ Complications } & \multirow{2}{*}{$\begin{array}{l}\text { Patient satisfied } \\
\text { with pain } \\
\text { reduction }\end{array}$} & \multirow{2}{*}{$\begin{array}{l}\text { Return to } \\
\text { work }\end{array}$} & \multirow{2}{*}{$\begin{array}{l}\text { Return to } \\
\text { sport }\end{array}$} & \multirow{2}{*}{$\begin{array}{l}\text { Follow- } \\
\text { up (mo) }\end{array}$} \\
\hline & & & Preop & Postop* & Preop & Postop* & Preop & Postop* & & & & & \\
\hline 1 & 42 & IV & 37 & 42 & $60 / 50$ & $60 / 80$ & 56 & 14 & None & Yes & Yes & Yes & 12 \\
\hline 2 & 47 & IV & 42 & 14 & $45 / 30$ & $70 / 25$ & 38 & 50 & $\begin{array}{l}\text { K-wire } \\
\text { infection }\end{array}$ & Yes & No & Yes & 14 \\
\hline 3 & 28 & IV & 21 & 13 & $45 / 45$ & $10 / 25$ & 68 & 37 & MUA & Yes & Yes & na & 12 \\
\hline 4 & 23 & IV & 12 & 18 & $60 / 50$ & $20 / 20$ & 30 & 35 & MUA & No & Yes & $\begin{array}{c}\text { No preop } \\
\text { sport }\end{array}$ & 14 \\
\hline 5 & 23 & IV & 9 & 19 & $70 / 70$ & $35 / 35$ & 40 & 28 & MUA & Yes & Yes & $\begin{array}{l}\text { No preop } \\
\text { sport }\end{array}$ & 20 \\
\hline 6 & 45 & IV & na & na & $45 / 45$ & $30 / 45$ & 51 & 32 & None & Yes & Yes & $\begin{array}{c}\text { No preop } \\
\text { sport }\end{array}$ & 15 \\
\hline Mean & 35 & IV & 24 & 21 & $54 / 48$ & $38 / 38$ & 47 & 33 & $66 \%$ & $83 \%$ & $83 \%$ & $100 \%$ & 15 \\
\hline
\end{tabular}

Abbreviations: preop, preoperatively; postop, postoperatively; na, non-available; K-wire, Kirschner wire; MUA, mobilisation under anesthesia.

*1 year postoperatively

This study has many limitations. First, and perhaps most importantly, only six patients were included in this study. Statistical analyses were not performed due to this small sample size. Secondly, there is no control group. Thirdly, the postoperative results aren't complete.

The PLI outcome was assessed by implant survival, physical examination and questionnaires. Implant survival was $100 \%$ at oneyear follow-up. The main indication for treatment was wrist pain, which was satisfactorily reduced in five patients. However, grip strength improved only slightly in three patients and moreover range of motion decreased in four patients at one-year follow-up. Despite these limitations, DASH scores reduced in four patients and five patients of the six patients could return to their previous jobs. These short-term results are suboptimal, especially considering that three out of six patients needed to be remobilized under general anaesthesia, probably largely due to severe stiffening of the wrist. The decreased range of motion could be the result of our postoperative treatment and might be avoided by a different postoperative treatment that would allow a shorter immobilization period and earlier range of motion exercises $[9,12]$. Although a higher risk of implant dislocation (one of 17 patients) [9] and malposition (2 of 11 patients) [12] could occur. Nonetheless, long-term results are necessary to adequately assess the longevity and functionality of this implant and to assess which postoperative treatment would provide the optimal clinical results. Until these results are published, we have abandoned this implant in our Hospital.

\section{Declaration}

- Ethics approval and consent to participate: This study was approved by the Medical Ethical Committee at the Amphia Hospital in Breda, The Netherlands.

- Availability of data and material: The datasets used and/or analysed during the current study are available from the corresponding author on reasonable request.

\section{References}

1. Kienbock R (1910) Uber traumatische Malazie des Monatbeins und ihre Folgezustande: Entartungsformen und Kompressionsfrakturen. Fortschrit Rontgenstrallen 16: 77.

2. Green DP, Hotchkiss RN, Pederson WC, Wolfe SW (2005) Green's Operative Hand Surgery, 5th edition. Philadelphia: Churchill Livingstone 2005:744-745.

3. Schmitt R, Krimmer H (2007) Osteonecrosis of the hand skeleton. In: Schmitt R, Ulrich L (Eds.), Diagnostic imaging of the hand. (1stedn), Stuttgart, New York, Georg Thieme Verlag Pg No: 351-64.

4. Luo J and Diao E (2006) Kienböck's disease. An approach to treatment. Hand Clin 22:465-73.

5. Lichtman DM, Lesley NE, Simmons SP (2010) The classification and treatment of Kienböck's disease: the state of the art and a look at the future. J Hand Surg [Eu] 35: 549-54.

6. Frangen TM, Konieczny MR, Gaggl AJ, Struewer J, Müller EJ, et al (2012) Semilunar bone necrosis (Kienböck's disease) - first clinical results after free microvascularised bone graft from the distal femur. Z Orthop Unfall.

7. Arora R, Lutz M, Zimmermann R, Struve P, Pechlaner S, et al (2010) Free vascularised iliac bone graft for Kienböck's disease stage III. Handchir Mikrochir Plast Chir 42: 198-203.

8. Mathoulin C, Haerle M, Vandeputte G (2005) Vascularized bone graft in carpal bone reconstruction. Ann Chir Plast Esthet 50: 43-48.

9. Visser NJ, de Wijn RS, Moojen TM, Feitz R (2017) Lunate implant arthroplasty: analysis of physical function and patient satisfaction. Eur J Plast Surg 40: 229-34. 
10. Kennedy CA, Beaton DE, Solway S, McConnell S, Bombardier C (2011) Disabilities of the Arm, Shoulder and Hand (DASH). The DASH and QuickDASH Outcome Measure User's Manual. Third Edition. Toronto, Ontario: Institute for Work \& Health 2011.

11. Viljakka T, Tallroth K, Vastamaki M (2014) Long-term outcome (22-36 years) of silicone lunate arthroplasty for Kienbock's disease. J Hand Surg Eur Vol 39: $405-415$.
12. Viljakka T, Tallroth K, Vastamaki M (2018) Long-Term Clinical Outcome After Titanium Lunate Arthroplasty for Kienbock Disease. J Hand Surg Am 43: 945.

13. Cook SD, Beckenbaugh RD, Redondo J, Popich LS, Klawitter JJ et al (1999) Longterm follow-up of pyrolytic carbon metacarpophalangeal implants. J Bone Joint Surg Am 81: 635-648.

\section{Citation:}

HJA Zijlker, R Fakkert, J van Rijn, A Beumer (2019) The Short-Term Results of Pyrocarbon Lunate Implants in Patients with Advanced Kienböck's Disease. Integr J Orthop Traumatol Volume 2 (3): 1-4. 